\title{
PEMBANGUNAN JALAN MAKAM RT. 01 RW.05 DESA KEDUNGLEPER KECAMATAN BANGSRI KABUPATEN JEPARA
}

\author{
${ }^{1)}$ Yayan Adi Saputro, ${ }^{2)}$ Muhammad Khoirul Mahfidh \\ ${ }^{1,2)}$ Program Studi Teknik Sipil, Fakultas Sains dan Teknologi, Universitas Islam Nahdlatul Ulama Jepara \\ ${ }^{1,2)}$ Jl. Taman Siswa (Pekeng) Tahunan Jepara \\ E-mail :yayan@unisnu.ac.id
}

\begin{abstract}
ABSTRAK
Kegiatan pengabdian masyarakat oleh dosen dan mahasiswa program studi Teknik Sipil Fakultas Sains dan Teknologi Universitas Islam Nahdlatul Ulama Jepara di RT. 01 RW. 05 Desa Kedungleper Kecamatan Bangsri ini adalah pembangunan jalan beton (rigid pavement) ke makam sepanjang $28 \mathrm{~m}$, lebar $3 \mathrm{~m}$, dan ketebalan $0,12 \mathrm{~m}$. Kegiatan yang dilaksanakan meliputi perencanaan, pelaksanaan, pengawasan, dan evaluasi. Perencanaan yang dilakukan oleh tim pengabdian ini bersama dengan tim pembangunan desa dan masyarakat membuat gambar dan RAB untuk diajukan ke musyawarah rencana pembangunan desa. Pelaksanaan yang dilakukan adalah setelah disetujuinya usulan yang diberikan dengan melibatkan bantuan masyarakat (swadaya masyarakat) dengan pembagian 2 bagian sesuai dengan hari. Dihari pertama sebanyak 16 orang untuk melakukan swadaya tenaga dan dihari ke 2 sebanyak 16 orang. Selama proses pelaksanaan dilakukan pengawasan mutu pekerjaan yang dihasilkan sehingga hasil yang diperoleh memiliki kualitas yang baik sesuai dengan perencanaan.
\end{abstract}

Kata Kunci: jalan baru, rigid pavement, swadaya masyarakat.

\begin{abstract}
Community service activities by lecturers and students of the Civil Engineering study program, Faculty of Science and Technology, Islamic University of Nahdlatul Ulama Jepara at RT. 01 RW. 05 Kedungleper Village, Bangsri District is the construction of a concrete road (rigid pavement) to the tomb along $28 \mathrm{~m}, 3 \mathrm{~m}$ wide, and $0.12 \mathrm{~m}$ thick. Activities carried out include planning, implementation, monitoring and evaluation. The planning carried out by this community service team together with the village and community development team made drawings and RABs to be submitted to the village development planning deliberations. The implementation is carried out after approval of the proposal given by involving community assistance (community self-help) in 2 parts according to the day. On the first day there were 16 people doing self-help and on the second day there were 16 people. During the implementation process, the quality of work produced is carried out so that the results obtained are of good quality according to the plan.
\end{abstract}

Keyword: new roads, rigid pavement, non-governmental organizations.

\section{PENDAHULUAN}

Desa Kedungleper merupakan salah satu desa yang berada di Kecamatan Bangsri Kabupaten Jepara. Letak Kecamatan Bangsri ini antara lain di Timur : Kecamatan Kembang, Barat : Kecamatan Mlonggo, Utara : Laut Jawa, Selatan : Kecamatan Pakisaji. Desa Kedungleper memiliki luas wilayah 309.156 ha, bertopografi dataran, berada $<500$ m diatas permukaan laut dan jarak Balai Desa ke Ibukota Kecamatan 2 km. Desa Kedungleper terbagi menjadi 6 RW dan 21 RT serta LKMD dengan kriteria berkembang. Pada tingkat sekolah dasar terdapat 2 SD Negeri 1 MI swasta. Untuk sekolah menengah pertama terdapat 1 MTs swasta. Sedangkan untuk sekolah menengah atas belum terdapat sarana pendidikan.

Mengingat desa kedungleper masih dalam proses perbaikan sarana dan prasarana, maka dibutuhkan pendampingan untuk mengelola dan meningkatkan kesadaran masyarakat dalam berpartisipasi untuk kemajuan bersama. Peningkatan sumberdaya manusia yang ada harus mampu menjawab segala permasalahan dan penginkatan kualitas. Sumber daya manusia menjadi foktor penting dalam memajukan sebuah kelompok, oleh karena itu upaya untuk mendorong hal ini perlu dipersiapkan dengan baik. Selain sumber daya manusia kualitas penunjang untuk melaksanakan aktifitas sehari-hari harus tercukupi dengan baik[1].

\begin{tabular}{lll}
\hline \hline DOI : https://doi.org/10.36341/jpm.v4i1.1474 & Some rights reservedBY-NC-SA 4.0 International License \\
\hline
\end{tabular}


Berkaitan dengan prasarana masyarakat yang ada di desa ini, maka pemerintah desa perlu mendorong msyarakatnya agar peduli dan bahu membahu memperbaiki kualitas tersebut. Salah satu contoh peningkatan prasarana adalah pada pekerjaan rabat beton jalan makam RT. 01 RW. 05 Desa Kedungleper yang didanai oleh dana desa. Pembangunan rabat beton ini bertujuan untuk meningkatkan aksesbilitas masyarakat dalam melakukan kegiatan keagamaan dan sosial. Adanya aksesbilitas ini akan mempermudah masyarakat dan meningkatkan kegiatan masyarakat dalam hal ziarah kubur. Kegiatan semacam ini merupakan warisan dari pendahulu sebagai bukti kepedulian dan ketaatan pada kebudayaan meliputi aspek rohaniah.

Adanya kegiatan ini perlu adanya pendampingan terhadap masyarakat untuk mengikuti prosedur dan proses yang diperlukan secara administrastif dilingkup pemerintahan. Sebagai upaya untuk meingkatkan hasil pembangunan tahapan-tahapan yang dilalui harus mampu terlaksana dengan baik, tahapan tersebut meliputi perencanaan, pelaksanaan, pengawasan, dan evaluasi hasil. Oleh karena itu tim pengabdian masyarakat dari Teknik Sipil Fakultas Sains dan Teknologi Universitas Islam Nahdlatul Ulama Jepara bermaksud mendampingi proses tersebut sehingga masyarakat dapat mengetahui proses yang harus dilalui. Selain itu memberikan contoh kepada masyarakat untuk selalu mengawal kegiatan desa dan memberi masukan yang baik untuk kemaslahatan bersama.

\section{TINJAUAN PUSTAKA}

UU nomor 34 tahun 2006 tentang Jalan. Disebutkan bahwa jalan adalah prasarana transportasi darat yang meliputi segala bagian jalan, termasuk di dalamnya bangunan pelengkap dan perlengkapan-nya yang diperuntukkan bagi lalu lintas, yang berada pada permukaan tanah, di atas permukaan tanah, di bawah permukaan tanah dan/atau air, serta di atas permukaan air, kecuali jalan kereta api, jalan lori, dan jalan kabel. Sebagai langkah mendukung beban lalulintas untuk didistribusikan kedalam tanah maka sebuah jalan perlu dilakukan perkerasan [2]. Secara umum ada 2 jenis perkerasan jalan yaitu rigid pavement dan fleksibel pavement.

\section{Rigid Pavement}

Perkerasan kaku ini adalah salat satu jenis konstruksi jalan dengan memanfaatkan bahan pengikat semen dengan berbagai bahan pengisi (pasir dan krikil) dan air untuk mendistribusikan beban kedalam tanah. Sesuai dengan namanya perkerasan kaku ini memiliki tingkat kekuatan yang tinggi bila dibandingkan dengan fleksibel pavement [3]. Secara umum ada 3 jenis pekersan kaku antara lain : Perkerasan kaku dengan sambungan tanpa tulangan, Perkerasan kaku dengan sambungan dan tulangan, Perkerasan kaku dengan tulangan tanpa sambungan [4].

\section{flexsibel Pavement}

Perkerasan lentur adalah salah satu jenis konstruksi jalan dengan menggunakan bahan aspal sebagai pengikat dan beberapa agregat kasar dan halus sebagai pengisi. Proses pembuatan pekerasan lentur ini ada yang menggunakan cara panas dan menggunakan cara dingin untuk proses pembuatannya. Ada banyak sekali jenis perkerasan lentur ini misalnya Lapis Aspal Beton (LASTON), Lapis Penetrasi Makadam (LAPEN), Lapis Asbuton Campuran Dingin (LASBUTAG), Hot Rolled Asphalt (HRA), aburan Aspal (BURAS), Laburan Batu Satu Lapis (BURTU), dan lain sebagainya [5].

\section{METODE PELAKSANAAN}

Kegiatan pengabdian ini dilakukan di makam RT. 01 RW. 05 Desa Kedungleper Kecamatan Bangsri Kabupaten Jepara. Rangkaian kegiatan ini adalah melakukan pendampingan dalam pembuatan jalan baru ke makam dengan pendekatan secara langsung dan melakukan tindakan langsung kepada masyarakat untuk melakukan pembangunan sesuai dengan rencana yang telah ditetapkan. Panjang jalan baru yang direncanakan adalah $28 \mathrm{~m}$, lebar $3 \mathrm{~m}$, dan ketebalan 0,12 $\mathrm{m}$. Jenis perkerasan yang digunakan untuk jalan tersebut adalah rigid pavement. Pemilihan jenis perkerasan ini didasarkan pada studi awal tentang kondisi tanah, lingkungan, anggaran dan 
sebagainya. Adapun dalam pengabdian ini ada beberapa tahapan yang dilakukan, semua tahapan itu akan menguraikan permasalahan dan pemecahan masalah yang tepat diloksi yang ditetapkan.

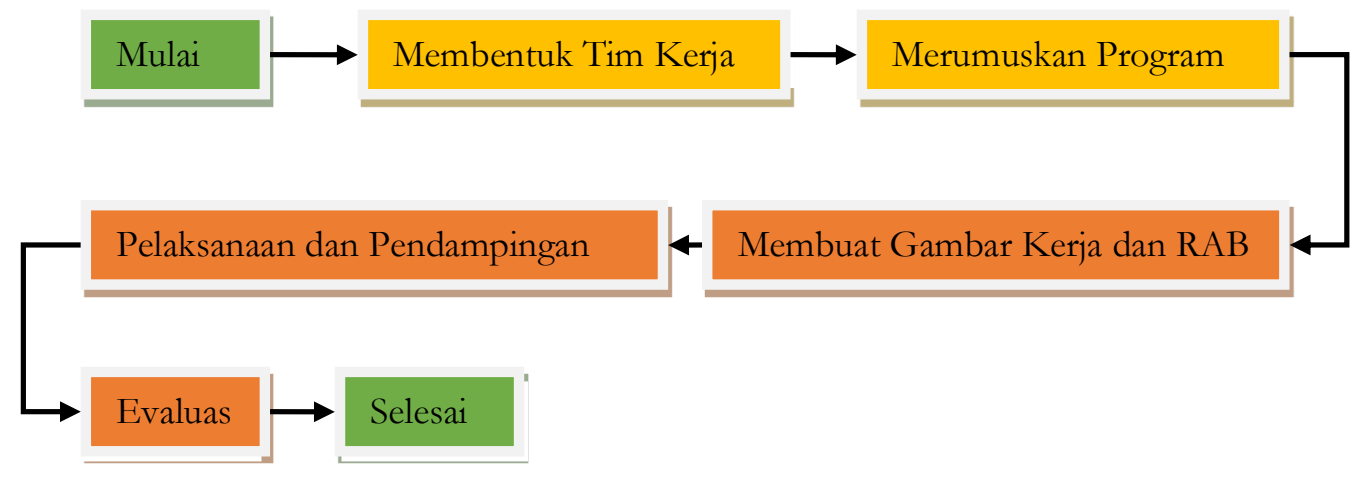

Gambar 1.Kerangka Kerja Kegiatan Pengabdian

Setelah melakukan pembentukan tim kerja yang terdiri dari tim dari universitas yang terdiri dari 1 mahasiswa dengan didampingi dosen, tim pelaksana kegiatan sesuai peraturan anggaran dana desa, dan tim pendamping dari kecamatan. Semua tim yang terlibat kemudian membuat gambar kerja dan RAB untuk diajukan di MUSRENBANGDES. Setelah usula itu diterima maka selanjutnya adalah dengan melaksanakan pembangunan dan melakukan evaluasi di semua tahapan yang dilaksanakan. Mobilitas tim pengabdian ini menjadi hal yang penting untuk menunjang keberhasilan berikut jarak tempuh tim pengabdian ke lokasi seperti pada gambar 2 .

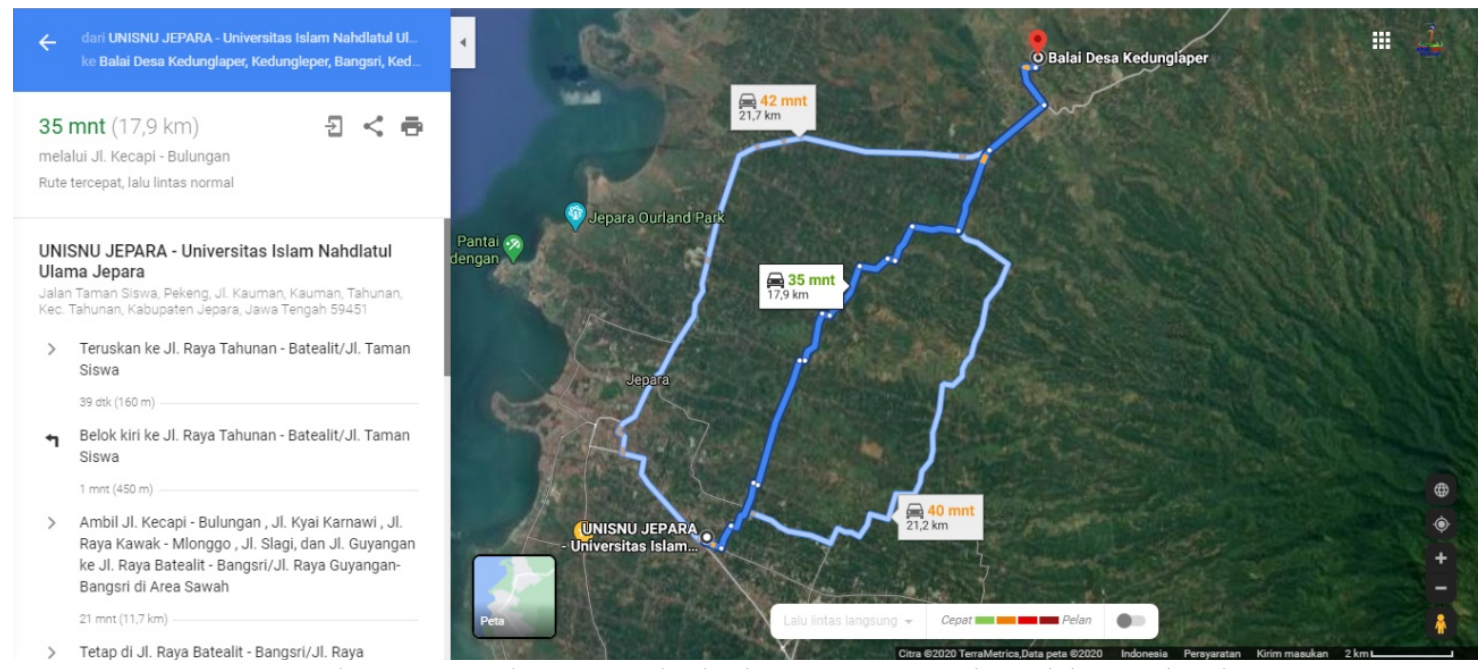

Gambar 2. Jarak Tempuh dari Perguruan Tinggi ke Lokasi

\section{HASIL PEMBAHASAN \\ Pra Pembangunan}

Sebelum melakukan pembangunan dilakukan peninjauan terhadap lokasi pembangunan oleh tim pengabdian dengan cara melakukan survey terhadap kondisi sekitar pembangunan. Adapun kondisi awal sebelum dilakukan pembangunan seperti pada gambar 3 . 

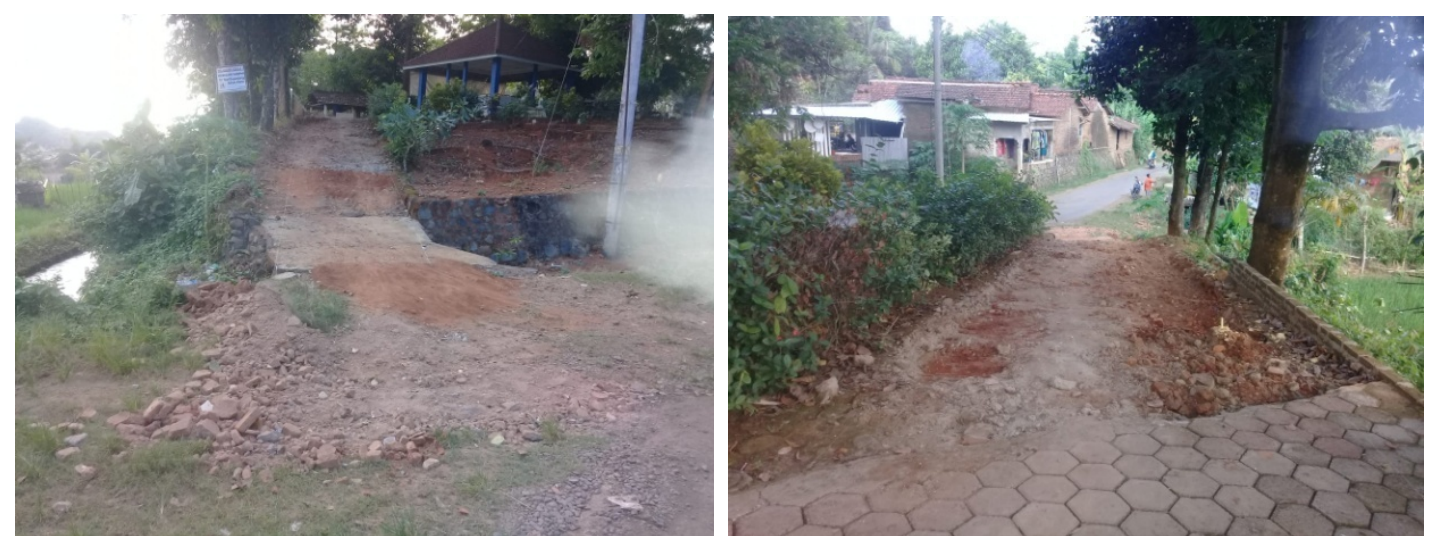

Gambar 3. Kondisi Awal Sebelum Pembangunan

Setelah data-data teknis dalam merencanakan terkumpul (lebar jalan, panjang jalan, kondisi tanah, drainase, dan lain-lain). Selanjutnya memastikan jenis perkerasan yang digunakan yaitu rigid pavement. Selanjutnya tim pengabdian melakukan perencanaan yang meliputi gambar kerja dan RAB. Berikut rekapitulasi anggaran biaya sesuai jenis belanja :

Tabel 1. Rencana Anggaran Biaya

\begin{tabular}{|c|c|c|c|}
\hline & & \\
\hline Uraian Kegiatan & Volume & Harga (Rp) & Jumlah Harga \\
\hline $\begin{array}{l}\text { Belanja Barang dan } \\
\text { Jasa } \\
\text { - Pekerjaan Persiapan } \\
\text { - Pekerjaan beton } \\
\text { - Pembersihan sisa } \\
\quad \text { pekerjaan }\end{array}$ & $\begin{array}{l}1 \text { unit } \\
1 \text { unit } \\
1 \text { unit }\end{array}$ & $\begin{array}{r}200.000 \\
2.040 .000 \\
100.000\end{array}$ & \\
\hline Total & & & 2.340 .000 \\
\hline $\begin{array}{l}\text { Belanja Modal } \\
-\quad \text { Pekerjaan Beton } \\
-\quad \text { Sewa Peralatan } \\
\end{array}$ & $\begin{array}{l}1 \text { unit } \\
1 \text { unit }\end{array}$ & $\begin{array}{l}7.477 .000 \\
1.183 .000 \\
\end{array}$ & \\
\hline Total & & & 8.660 .000 \\
\hline Total Keseluruhan & & & 11.000 .000 \\
\hline
\end{tabular}

Sumber : Rencana Anggaran Biaya, 2020

Panjang jalan yang direncanakan adalah $28 \mathrm{~m}$ dengan lebar $3 \mathrm{~m}$ serta ketebalan jalan rigid pavement $0,12 \mathrm{~m}$. Untuk lebih jelasnya dpat dilihat pada gambar 4 . dibawah ini :

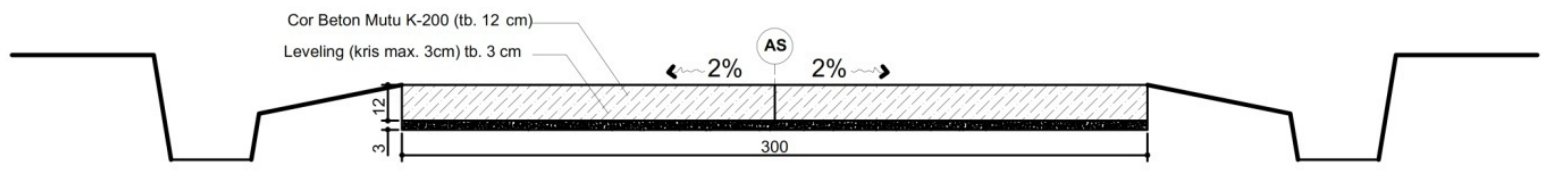

Gambar 4. Potongan melintang jalan

Pendanaan pada kegiatan ini adalah dibiayai oleh Anggaran Dana Desa Kedungleper Kecamatan Bangsri Kabupaten Jepara. Sebagai upaya untuk mendukung hasil kegiatan ini masyarakat melakukan swadaya sehingga meningkatkan hasil pekerjaan. Bentuk swadaya yang dilakukan adalah dengan membantu tenaga.

\section{Pelaksanaan pembangunan}

Pelaksanaan dilakukan selama 2 hari kerja yakni mulai tanggal 25-26 Juli 2020, masyarakat 
RT.01 RW.05 Desa Kedungleper dibagi kedalam 2 bagian yakni bagian pertama pada hari pertama dan bagian yang kedua di hari kedua. Masing-masing bagian terdiri dari 16 orang. Adapun material yang dibutuhkan untuk menyelesaikan pembangunan ini adalah sebagai berikut:

Tabel 2. Bahan yang digunakan

\begin{tabular}{|c|l|c|}
\hline No & \multicolumn{1}{|c|}{ Nama Material } & Jumlah \\
\hline 1 & Semen $(50 \mathrm{~kg})$ & $34 \mathrm{Zak}$ \\
\hline 2 & Pasir beton & $5 \mathrm{~m} 3$ \\
\hline 3 & Kris / Split & $6 \mathrm{~m} 3$ \\
\hline 4 & Air & $1500 \mathrm{ltr}$ \\
\hline 5 & Plastik & $68 \mathrm{~m} 2$ \\
\hline 6 & Kayu Randu tebal 2 & $20 \mathrm{lbr}$ \\
\hline 7 & Paku biasa 2"-5” & $5 \mathrm{~kg}$ \\
\hline
\end{tabular}

Sumber : Laporan Pelaksanaan Kegiatan, 2020

Melakukan pembangunan dengan melibatkan masyarakat sebagai upaya untuk mengaktifkan sikap gotong royong dalam masyarakat menimbulkan hal yang positif baik itu disisi masyarakat itu sendiri maupun disisi hasil pembangunannya.

Berikut ini hasil pembangunan makam 100\%.
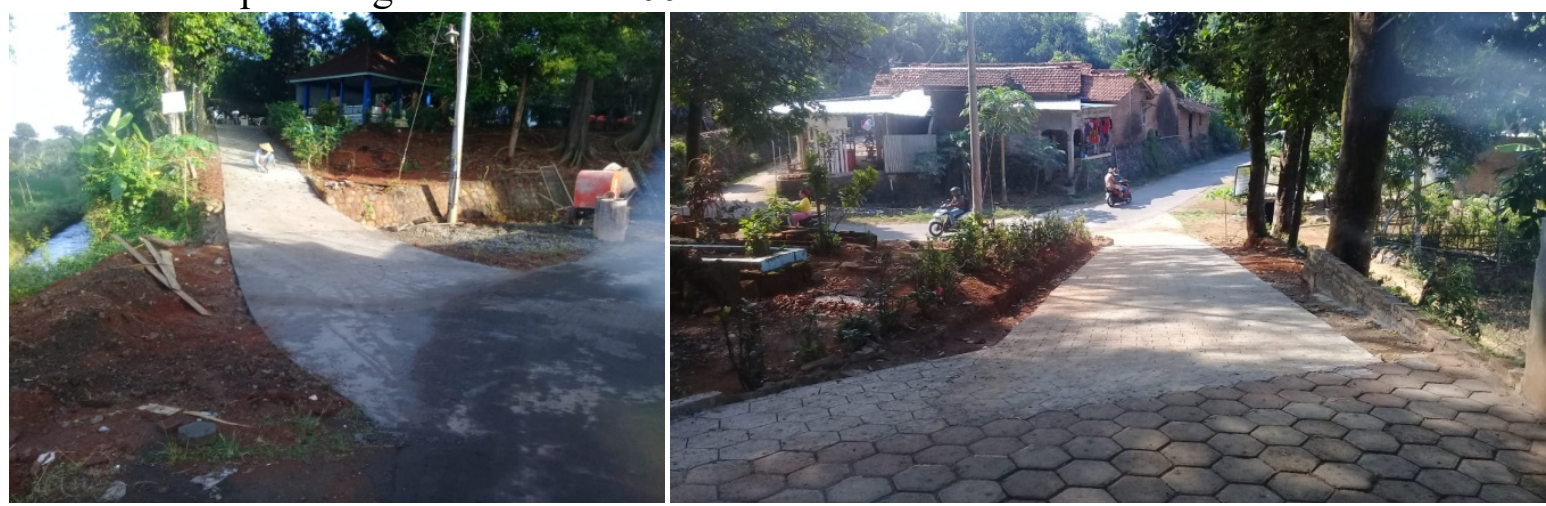

Gambar 4. Hasil Setelah Pelaksanaan

\section{KESIMPULAN}

Pembangunan jalan makam di RT. 01 RW. 05 ini didanai oleh dana desa dan swadaya masyarakat. Tim pengabdian bertugas mengawal mulai dari pengusulan di MUSRENBAGDES sampai tahap pekerjaan pembangunan jalan tersebut. Salah satu bentuk pengabdian masyarakat dalam kegiatan ini adalah memberikan pendidikan kepada masyarakat untuk mengawal dana desa dengan baik dan berpartisipasi dalam pelaksanaannya. Tim pegabdian membantu merancang gambar kerja dan RAB secara mendetail agar pelaksananaan pembangunan berjalan dengan baik. Hasil dari pengabdian masyarakat ini mendorong keaktifan masyarakat dalam berperan aktif untuk melakukan proses mulai dari perencanaan, pelaksanaan, dan pengawasan pada pembangunan jalan makam. Hal ini dimaskudkan agar aksesbilitas ke area makam dapat lebih mudah dan nyaman. Selain itu memberikan dukungan kepada masyarakat untuk aktif pada kegiatan atau program yang lainnya.

\section{DAFTAR PUSTAKA}

[1] H. Mubarak, "Pelebaran Jalan Umum Dalam Komplek Perumahan Limbungan Permai (Plp) Rt.02 Rw.06 Kelurhan Lembah Sari Kecamatan Rumbai Pesisir Pekanbaru Riau," Apollo, vol. 190, no. 679, pp. 80-86, 2019, doi: 10.5040/9781350185555.ch-012.

[2] D. I. Kabupaten and A. Utara, "Strategi pengelolaan infrastruktur jalan di kabupaten aceh utara," vol. 7, no. 1, pp. 153-162, 2017. 
[3] W. Wahab, D. Jurusan, and T. Sipil, "Jurnal Momentum ISSN : 1693-752X STUDI Kelayakan Peningkatan Kapasitas Ruas Jalan Soekarno Hatta - Havid Jalil Kota Bukittinggi Jurnal Momentum ISSN : 1693-752X," vol. 16, no. 1, pp. 8-18, 2014.

[4] K. Erwan, E. T. Mukti, and R. S. Suyono, "Tinjauan Geometrik Jalan Dan Kinerja Jalan Dalam Penentuan Rute Pergerakan Angkutan Barang ( Studi Kasus : Kota Pontianak )," 1999.

[5] B. Muljo, S. Dan, and H. Kustarto, "Perbaikan Geometrik Trase Jaringan Jalan Dengan Menggunakan Teknologi Penginderaan Jauh Dan Sistem Informasi Geografis," J. Makara Sains, vol. 6, no. 3, pp. 136-141, 2002. 